\title{
Improved Voltage Control of the Electric Vehicle Operating as UPS in Smart Homes
}

\author{
Vítor Monteiro $^{1}$, J. P. S. Catalão ${ }^{2}$, Tiago J. C. Sousa ${ }^{1}$, J. G. Pinto ${ }^{1}$, \\ Marcello Mezaroba ${ }^{3}$, João L. Afonso ${ }^{1}$ \\ ${ }^{1}$ ALGORITMI Research Centre, University of Minho, Guimarães - Portugal \\ ${ }^{2}$ INESC TEC and Faculty of Engineering of the University of Porto, Porto - Portugal \\ ${ }^{3}$ Santa Catarina State University, Joinville - Brazil \\ vmonteiro@dei.uminho.pt
}

\begin{abstract}
As a contribution for sustainability, electric vehicles (EVs) are seen as one of the most effective influences in the transport sector. As complement to the challenges that entails the EVs integration into the grid considering the bidirectional operation (grid-to-vehicle and vehicle-to-grid), there are new concepts associated with the EV operation integrating various benefits for smart homes. In this sense, this paper proposes an improved voltage control of the EV operating as uninterruptible power supply (UPS) in smart homes. With the EV plugged-in into the smart home, it can act as an off-line UPS protecting the electrical appliances from power grid outages. Throughout the paper, the foremost advantages of the proposed voltage control strategy are comprehensively emphasized, establishing a comparison with the classical approach. Aiming to offer a sinusoidal voltage for linear and nonlinear electrical appliances, a pulse-width modulation with a multi-loop control scheme is used. A Kalman filter is used for decreasing significantly the time of detecting power outages and, consequently, the transition for the UPS mode. The experimental validation was executed with a bidirectional charger containing a double stage power conversion (an ac-dc interfacing the grid-side and a dc-dc interfacing the batteries-side) and a digital stage. The computer simulations and the acquired experimental results validate the proposed strategy in different conditions of operation.
\end{abstract}

Keywords: Electric Vehicle, Bidirectional Converter, Uninterruptible Power Supply, Kalman Filter, Smart Home.

\section{Introduction}

The intensification use of electric vehicles (EVs) leads to new challenges for the grid controlling with respect to the energy needed for the batteries charging (grid-to-vehicle, G2V mode), particularly when assuming a substantial amount of VEs plugged-in [1][2][3]. As example, a strategy to minimize the peak load caused by a fleets of EVs is presented in [4], the contribution of EVs for demand response in distributed power grid is proposed in [5], an analysis of the EVs integration through 
different dynamics in the power grid is presented in [6], and a review of the impact caused by EVs on distribution power grid is presented in [7]. In response to the G2V and V2G tasks that the EVs incorporation entails, and with the creation of the communication network connecting all the players, there are new opportunities in terms of distributed storage to help to stabilize the power grid operation [8]. Some of these opportunities are related with distributed energy resources (DER) in microgrids: the collective process of EVs and solar PV panels for the energy generation portfolio is analyzed in [9], a DER with EVs controlled by a collaborative broker is presented in [10], an EV charging on an office building with DER is presented in [11], a smart distribution grid with EVs is experimentally analyzed in [12], and optimized energy management of EVs in microgrids is presented in [13]. In these circumstances are expected EVs prepared to accomplish a bidirectional operation, i.e., consuming or delivering energy from or to the grid (vehicle-to-grid, V2G mode) [14][15]. Besides the bidirectional operation, new concepts for the EV functioning in smart grids and smart homes are emerging [16][17], highlighting assistances for improving power quality [18][19].

In addition to the G2V and V2G modes, the spread of the EVs will also consent the emergence of new concepts for the EV utilization framed with new technologies for smart homes. One of these new concepts is the possibility of the EV operation as an uninterruptible power supply (UPS). This option is only accessible when the EV is plugged-in at the smart home. Since in this operation mode the EV is used to provide additional functionalities for the smart home, it is identified as vehicle-to-home (V2H). This operation mode consists in use the energy stored in the EV batteries to supply the electrical appliances during power outages, which is different of the scheduling management between EVs and electrical appliances [20][21]. The V2H operation mode was initially proposed for isolated locations, where there is no connection to the grid, however, without the UPS functionality [22]. Commercially, this concept was initially introduced by Nissan under the name "LEAF-to-Home", however, it requires a "EV Power Station", letting the V2H approach only where it is installed, but it does not allow the operation as a UPS in case of power outages. The possibility of the V2H mode as UPS was introduced in [23], however, without a satisfactory experimental validation in terms of synthetized voltage in the UPS mode. The main contributions of this paper are: Improved voltage control of the EV operating as UPS in smart homes; Faster transient from the G2V to the V2H mode; Experimental validation of the EV charger prototype operating with the proposed voltage control.

The paper is organized as follows. After the contextualization, section II presents the EV integration, section III introduces a description of the EV charger, section IV presents the multi-loop voltage control for the $\mathrm{V} 2 \mathrm{H}$ mode, section $\mathrm{V}$ presents the most relevant experimental results, and, finally, section VI presents the main conclusion.

\section{EV Integration into Smart Homes}

In a smart home perspective, the operation of some of the electrical appliances are on/off controlled according to the energy management and the user comforts and 
conveniences. These electrical appliances require two fundamental things for a properly operation: power and an internal communication. Since the EV is plugged-in at the smart home, in case of power outages, it can provide uninterrupted power for the electrical appliances according to the battery state-of-charge (cf. section I). However, in order to prevent a fully battery discharging, some of electrical appliances can be turned-off at the same time of the power outage occurrence (e.g., heating systems or secondary lights), but others not (e.g., internal communication system, main lights, or the alarm system). The criteria to select the electrical appliances supplied by the V2H mode as UPS is established by the smart home energy management. The introduction of the EV charger into a smart home during the operation in G2V mode (charging the batteries) and in $\mathrm{V} 2 \mathrm{H}$ mode (as an off line UPS to supply the smart home electrical appliances) is presented in Fig. 1.
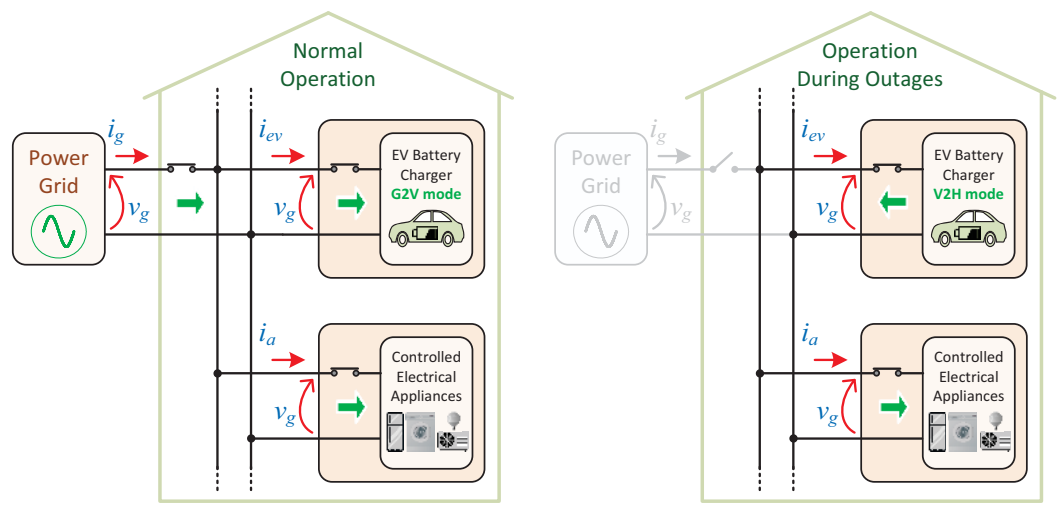

Fig. 1. Introduction of the EV charger into a smart home during: (a) Operation in G2V mode (charging the batteries); (b) Operation in V2H mode (as an off-line UPS to supply the smart home electrical appliances).

\section{EV Battery Charger Description}

In a smart home perspective arises the occasion to integrate a bidirectional EV charger with new functionalities, representing a pertinent influence for the home energy management. Therefore, the presented EV charger also allows the V2H mode as an off-line UPS. In the scope of this paper, the developed EV charger comprises two power converters linked by a dc-link. One of the converters interfaces the grid-side and the other interfaces the batteries-side. For the converter that interfaces the power grid a fully-controlled active full-bridge rectifier is used to make the current consumption sinusoidal with unitary power factor (in $\mathrm{G} 2 \mathrm{~V}$ and $\mathrm{V} 2 \mathrm{G}$ modes) [24][25][26][27]. During the V2H mode as an UPS, the ac-dc converter operates as a voltage source controlled to synthesizing a voltage signal with the amplitude and frequency needed to supply the electrical appliances connected in the smart home. The converter that interfaces the batteries (dc-dc), during the G2V mode, acts as a buck converter, controlling the periods of the battery charging. During the V2G mode, 
it acts as a boost converter, discharging the batteries. During the V2H mode as an UPS, the dc-dc converter is responsible for regulating the voltage of the dc-link for the correct operation of the ac-dc converter.

The introduction of the EV charger into a smart home is presented in Fig. 2, showing the internal arrangement of the EV charger, where LC low-pass filters are used at the grid-side and at the batteries-side to filter the high frequencies produced by the converters. In the grid-side, targeting to smooth the gain response of the LC filter at the cut-off frequency, a damping resistor is used in series with the capacitor. In the battery-side, a capacitor with low equivalent series resistor is used, targeting to attain a low current ripple in the batteries. All of the semiconductors (IGBTs) are switched at $20 \mathrm{kHz}$ and the components were selected establishing a conciliation among the filter performance and size.

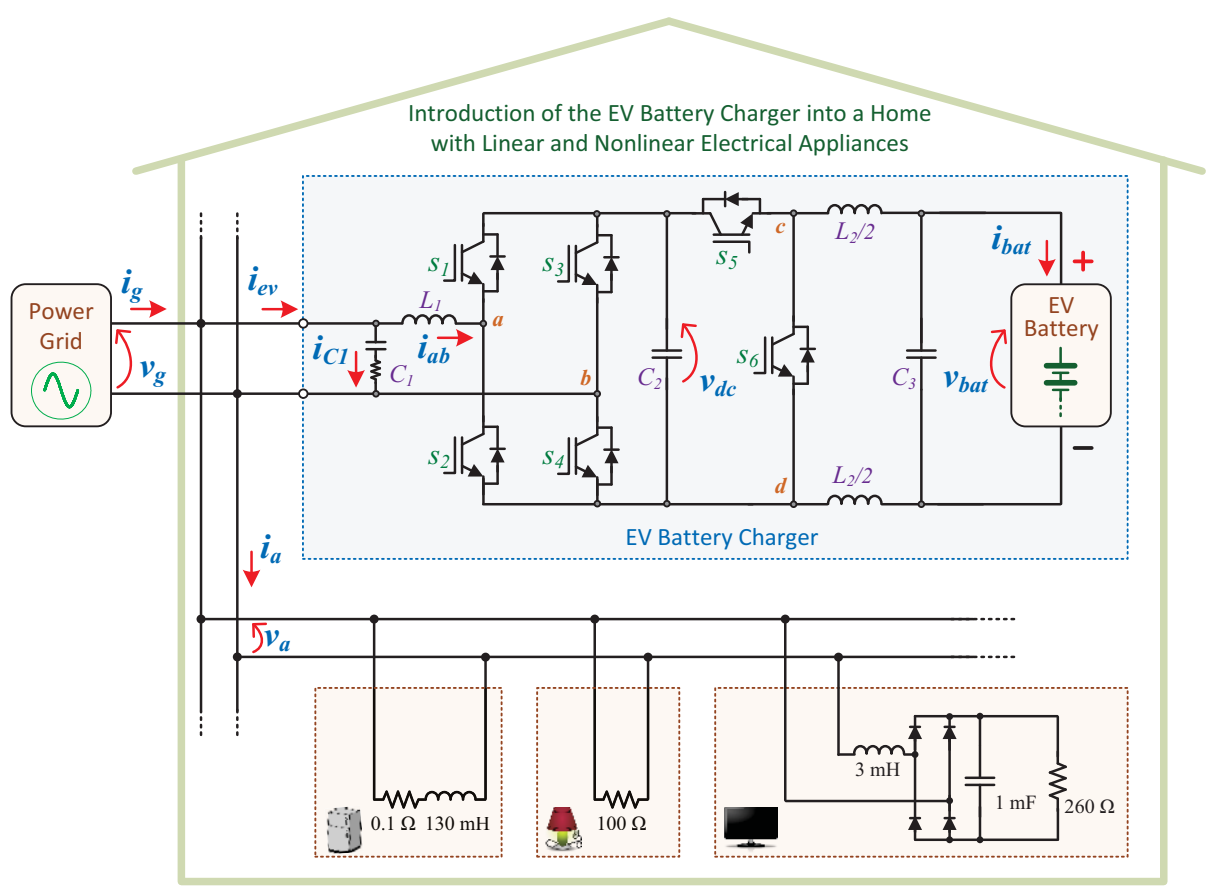

Fig. 2. Introduction of the EV charger into a smart home and its internal arrangement in terms of power electronics converters.

\section{Multi-Loop Voltage Control}

A meticulous explanation of the proposed multi-loop voltage control applied to the V2H mode as UPS is introduced in this section, which is based on a predictive control strategy deducted from the circuit topology shown in Fig. 2. The multi-loop voltage control has as main purpose the EV charging control for producing an ac-side voltage with the nominal rms and frequency values of the grid voltage, i.e., the nominal val- 
ues before the outage. Since the proposed algorithm does not require any gain in its modulation, it is only dependent of the converter parameters, represents a pertinent benefit due to the unpredictability operation of the linear or nonlinear electrical appliances connected into the home. By applying the first Kirchhoff law, the relation among the grid-side current $\left(i_{e v}\right)$, the current in the passive filter $\mathrm{C} 1\left(i_{C I}\right)$, and the current of the converter $\left(i_{a b}\right)$, can be expressed by:

$$
i_{e v}=i_{C 1}+i_{a b} .
$$

On the other hand, in order to obtain the relation among the voltage produced by the converter (denoted by $v_{a b}$ in Fig. 2), the voltage in the passive filter L1 $\left(v_{L I}\right)$, and the voltage applied to the electrical appliances is used the second Kirchhoff law, as expressed by:

$$
v_{a b}=-v_{L 1}+v_{g} .
$$

Since the voltage across the inductor $L_{l}$ is expressed by:

$$
v_{L 1}=L_{1} \frac{d i_{a b}}{d t}
$$

substituting the equation (3) in the equation (1) is attained the subsequent relation:

$$
v_{a b}=-L_{1} \frac{d i_{a b}}{d t}+v_{g} .
$$

Knowing that the current $i_{a b}$ is provided by the equation (1), and existing the possibility to determine the current in the capacitor $C_{l}$ using the equation (it was considered that the damping resistor is negligible):

$$
i_{C 1}=C_{1} \frac{d v_{g}}{d t}
$$

the final equation is obtained from:

$$
v_{a b}=-L_{1} \frac{d}{d t}\left(i_{e v}-C_{1} \frac{d v_{C 1}}{d t}\right)+v_{g} .
$$

Reorganizing the terms of equation (6), and considering the grid side voltage $\left(v_{g}\right)$ equal to the voltage variation at the capacitor $C_{l}$, is obtained the equation:

$$
v_{a b}=L_{1} C_{1} \frac{d^{2} v_{g}}{d t^{2}}-L_{1} \frac{d i_{e v}}{d t}+v_{g}
$$

The derivatives can be estimated by linear variations without leading noteworthy error due to the high sampling frequency. Therefore, the equation (7) is simplified for:

$$
\begin{aligned}
v_{a b} & =\frac{L_{1} C_{1}}{T_{a}{ }^{2}}\left(v_{g}{ }^{*}[k]-2 v_{g}[k]+v_{g}[k-1]\right)- \\
& +\frac{L_{1}}{T_{a}}\left(i_{e v}[k]-i_{e v}[k-1]\right)+v_{g}[k] .
\end{aligned}
$$




\section{Experimental Results}

In this section, the experimental results of the tests that were carried out with the EV charger are presented. These results were attained for validating the proposed multiloop voltage control presented in section IV, mainly, under the V2H mode as UPS. Fig. 3 shows the laboratory workbench where all the experimental tests were carried out. It should be noted that all the experimental results were obtained using the Yokogawa DL708E oscilloscope.

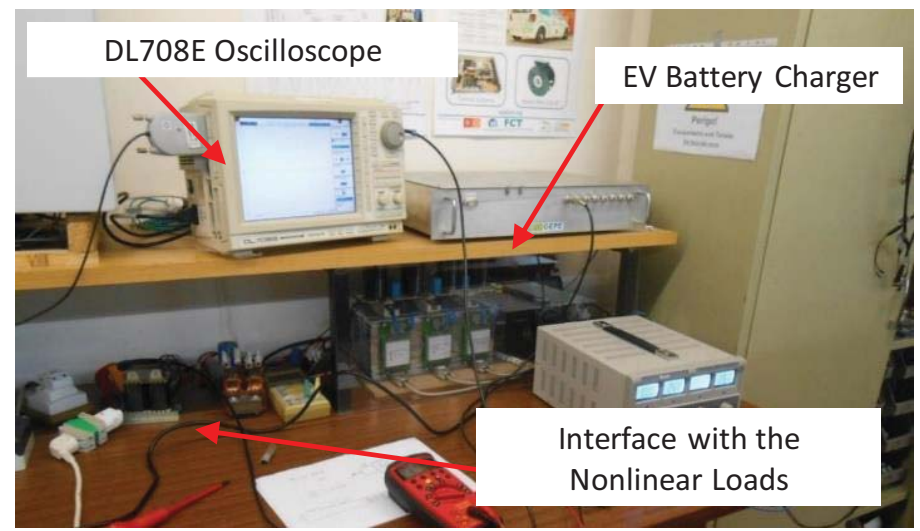

Fig. 3. Laboratory workbench used for the experimental tests.

With the purpose to control the EV charger according to the objectives outlined, it is indispensable to implement a synchronization algorithm with the fundamental component of the grid voltage. Thereby, a phase locked-loop (PLL) was used to attain such synchronization. In Fig. 4(a), it can be observed the synchronism of the PLL signal $\left(v_{P L L}\right)$ with the grid voltage during $50 \mathrm{~ms}$. It should be noted that this result was attained in steady state, i.e., after the PLL is completely synchronized with the voltage. A detail of both signals is presented in Fig. 4(b).

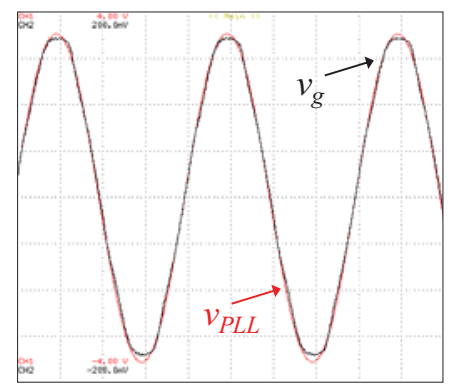

(a)

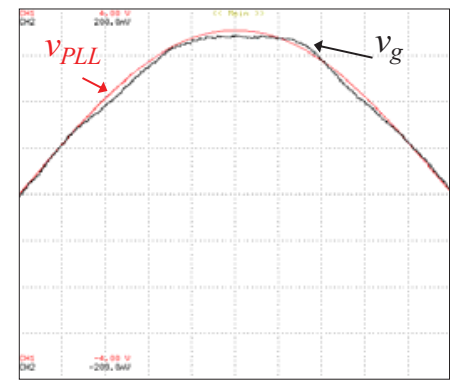

(b)

Fig. 4. Experimental results: (a) Synchronism of the PLL signal $\left(v_{P L L}\right)$ with the power grid voltage $\left(v_{g}\right)$; (b) Detail of both signals. 
As mentioned in section II, the current control strategy for the ac-dc converter of the EV charger needs a sinusoidal reference, which is compared with the measured grid-side current for obtaining the PWM signals of the IGBTs. As validate through the result shown in Fig. 5(a), the grid-side current is sinusoidal with the same phase of the voltage, demonstrating the excellent operation of the current control loop. In order to charge the EV batteries, a constant reference of current was selected. As can be validated through the Fig. 5(b), in steady, the charging current state is constant, validating the current control and the operation of the dc-dc converter. However, as can be seen in figure, the reference of current value does not immediately take the maximum value, i.e., the value is gradually increased until reaching the desired value. This plan is used in order to prevent oscillations of the dc-link voltage, which was perfectly achieved, as demonstrated in this figure.

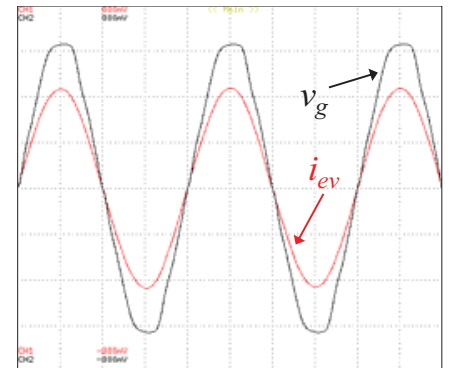

(a)

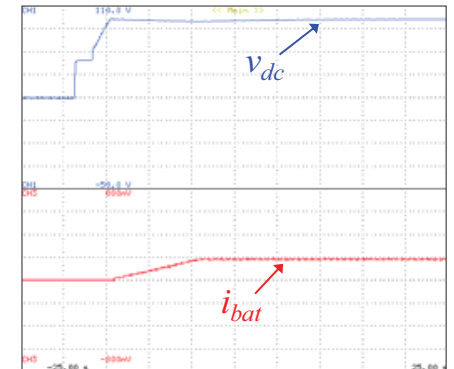

(b)

Fig. 5. Experimental results: (a) Power grid voltage $\left(v_{g}\right)$ and EV current $\left(i_{e v}\right)$ in G2V mode; (b) EV battery current $\left(i_{b a t}\right)$ and dc-link voltage $\left(v_{d c}\right)$ in the G2V mode.

During the tests carried out with the EV charger operating in the V2H mode, a comparison was established in terms of the calculation of the rms voltage using a traditional method and a method based on the Kalman filter. The main purpose of this comparison was to verify if the calculation based on the Kalman filter is faster than the traditional approach. A set of computer simulations were obtained for different amplitudes of outages and considering its occurrence in different angles of the voltage, showing that the Kalman filter offers better results for all the operating scenarios. However, since this study is out of the scope of this paper, they were omitted. Therefore, an experimental validation was carried out using a Kalman filter. As can be validated through the Fig. 6, the power outage was detected by the control system about in $0.4 \mathrm{~ms}$ after the outage, time in which the EV charger starts its operation as energy source, i.e., the required time for the operation as UPS.

In order to confirm the EV charger operation and to evaluate the performance of the multi-loop voltage control in V2H mode as UPS considering a real scenario, linear and nonlinear electrical appliances were used in the experimental validation. The tests began with a representative linear electrical appliance of heating systems (in the laboratory, a resistor of $26 \Omega$ was selected for such purpose). In Fig. 7(a) can be observe the voltage synthesized by the EV charger and applied to the linear electrical appliance, as well as the consumed current. In this first test the voltage synthesized by 
the EV charger is totally sinusoidal, does not present any distortion as intended, thus being validated the multi-loop voltage control applied to the ac-dc converter. After the initial test performed with a linear electrical appliance, experimental tests were carried out with nonlinear electrical appliances to evaluate the proposed multi-loop voltage control. In Fig. 7(b) it is possible to observe the results of this experimental test, where a resistive load with a value of $26 \Omega$ and a diode rectifier with a capacitive output filter with a capacitance value of $470 \mu \mathrm{F}$ are coupled to the EV charger during the operation as UPS. As shown in the result obtained in Fig. 7(b), due to the proposed multi-loop voltage applied to the ac-dc converter, it was possible to synthesize a sinusoidal voltage with reduced harmonic distortion.

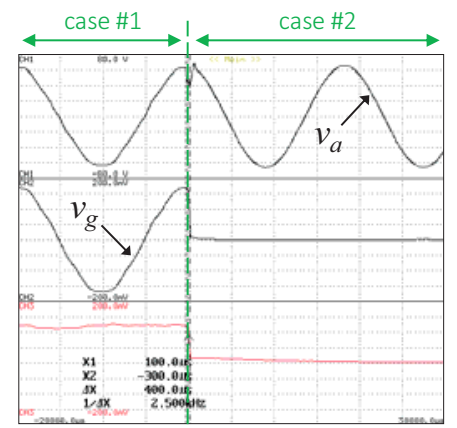

Fig. 6. Experimental result showing the detection of a power outage and the beginning of the V2H mode as UPS.

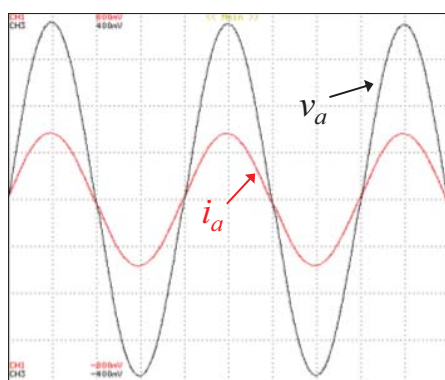

(a)

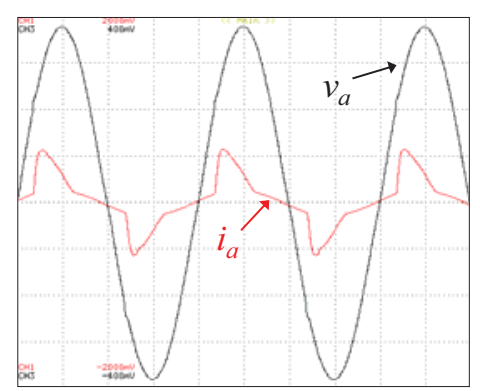

(b)

Fig. 7. Experimental results of the produced voltage $\left(v_{a}\right)$ and consumed current $\left(i_{a}\right)$ during the V2H mode as UPS considering: (a) linear electrical appliances; (b) nonlinear electrical appliances.

During the tests performed on the EV charger operating as an UPS, the dc-link voltage and the current in the EV batteries were also analyzed in order to see if the dc-link voltage control is operating correctly. The result of this experimental test can be seen in Fig. 8. Initially, the dc-link regulation is achieved through the EV charger operating as G2V. When the dc-link voltage is at its reference value a power outage occurs and, subsequently, the charging is interrupted, the EV charger is unplugged from the 
grid and initiates the operation in V2H mode as UPS. As shown in Fig. 8(a), during the transition from the G2V mode to the V2H mode as UPS, a voltage sag in the dc-link occurs, which is readily recovered by the control algorithm inherent to the dc-dc converter, keeping the dc-link voltage at a steady state voltage close to the defined reference. It should be noted that the voltage sag on the dc-link can be minimized, however, the discharging current of the batteries at that time would have a high current peak. Taking into account this factor, a cost-benefit ratio was chosen, opting to reduce the peak current of the batteries and increase the voltage sag of the dc-link during the transition from operating modes. In Fig. 8(a) it is also possible to verify the discharging current with a constant stage during the operation in the V2H mode as UPS. It should be noted that throughout the V2H mode, and for all the electrical appliances, the result of the dc-link voltage and of the EV battery current is comparable, changing only the discharge value of the batteries. In addition to the above-mentioned results, a shift from the $\mathrm{V} 2 \mathrm{H}$ to the G2V mode was attained. As shown in Fig. 8(b), a transition is obtained without the existence of any type of transient, either in the current or in the voltage. This is because the transition does not happen instantly after the power grid is reestablished, but rather after the signal resulting from the PLL is fully synchronized with the grid voltage and the control system waits a period of $5 \mathrm{~s}$ in order to verify that there were no other power grid outages.

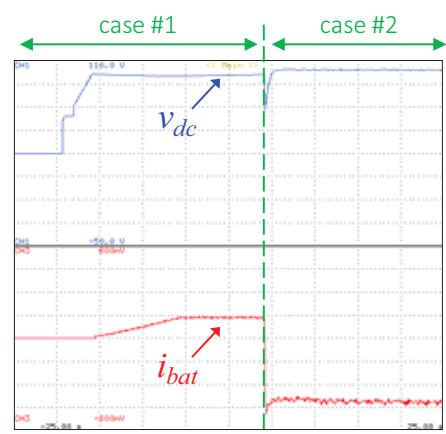

(a)

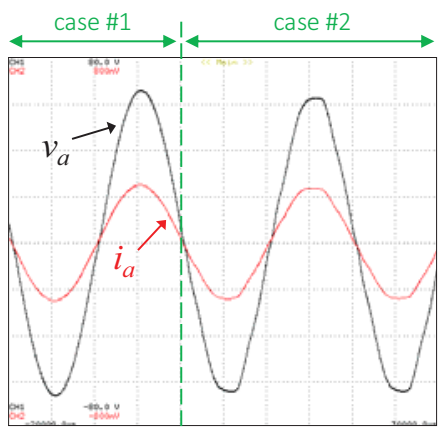

(b)

Fig. 8. Experimental results: (a) EV battery current $\left(i_{b a t}\right)$ and dc-link voltage $\left(v_{d c}\right)$ in the G2V mode during the transition of the G2V mode to the V2H mode as UPS; (b) Voltage ( $v_{a}$ ) and current $\left(i_{a}\right)$ in the electrical appliances during the transition from the $\mathrm{V} 2 \mathrm{H}$ mode to the normal mode.

\section{Conclusions}

An improved voltage control for the electric vehicle (EV) operation in vehicle-to-home (V2H) mode as an off-line uninterruptible power supply (UPS) is proposed in the context of smart homes. The V2H mode as UPS represents a complement to the challenges that entails the EVs integration into the grid, representing a pertinent benefit for smart homes, since the EV can be used for protecting the electrical appliances from grid outages. The voltage control is based on a predictive control strategy, 
deducted from the circuit topology of the EV charger. Its main purpose consists in establish an ac-side voltage with the nominal $\mathrm{rms}$ and frequency values of the grid voltage. An EV battery charger based on a double stage power conversion was developed for the experimental validation, showing the correct action in the $\mathrm{V} 2 \mathrm{H}$ mode as UPS, mainly characterized by a fast transition from the normal mode to the UPS mode and by a sinusoidal voltage even with nonlinear loads.

\section{Acknowledgment}

This work has been supported by COMPETE: POCI-01-0145-FEDER-007043 and FCT - Fundação para a Ciência e Tecnologia within the Project Scope: UID/CEC/00319/2013. This work is financed by the ERDF - European Regional Development Fund through the Operational Programme for Competitiveness and Internationalisation - COMPETE 2020 Programme, and by National Funds through the Portuguese funding agency, FCT - Fundação para a Ciência e a Tecnologia, within project SAICTPAC/0004/2015 - POCI - 01-0145-FEDER-016434. This work is part of the FCT project 0302836 NORTE-01-0145-FEDER-030283.

\section{References}

1. Vítor Monteiro, João C. Ferreira, Andrés A. Nogueiras Meléndez, João L. Afonso, "Electric Vehicles On-Board Battery Charger for the Future Smart Grids," in Technological Innovation for the Internet of Things, 1st ed., Luis M. Camarinha-Matos, Slavisa Tomic, Paula Graça, Ed. Springer, 2013, Chapter 38, pp.351-358.

2. Vítor Monteiro, Henrique Gonçalves, João L. Afonso, "Impact of Electric Vehicles on Power Quality in a Smart Grid Context," IEEE EPQU International Conference on Electrical Power Quality and Utilisation, pp.1-6, Oct. 2011.

3. João C. Ferreira, A. Silva, Vítor Monteiro, João L. Afonso. "Collaborative Broker for Distributed Energy Resources," in Computational Intelligence and Decision Making, 1st ed., A.Madureira, C.Reis, V.Marques, Ed. Springer, 2013, pp.367-378

4. V. L. Nguyen, T. Tran-Quoc, S. Bacha, and B. Nguyen, "Charging Strategies to Minimize the Peak Load for an Electric Vehicle Fleet," IECON 2014 - 40th Annual Conference of the IEEE Industrial Electronics Society. IEEE, pp. 3522-3528, Oct-2014.

5. Y. Wang, O. Sheikh, B. Hu, C.-C. Chu, and R. Gadh, "Integration of V2H/V2G Hybrid System for Demand Response in Distribution Network," 2014 IEEE International Conference on Smart Grid Communications (SmartGridComm). IEEE, pp. 812-817, Nov-2014.

6. J. A. P. Lopes, F. J. Soares, and P. M. R. Almeida, "Integration of Electric Vehicles in the Electric Power System," Proceedings of the IEEE, vol. 99, no. 1. pp. 168-183, Jan-2011.

7. R. C. Green, Lingfeng Wang, and M. Alam, "The Impact of Plug-in Hybrid Electric Vehicles on Distribution Networks: A Review and Outlook," IEEE PES General Meeting, vol. 15, no. 1. IEEE, pp. 1-8, Jul-2010.

8. Jun Hua Zhao, Fushuan Wen, Zhao Yang Dong, Yusheng Xue, Kit Po Wong, "Optimal Dispatch of Electric Vehicles and Wind Power Using Enhanced Particle Swarm Optimization,” IEEE Trans. Ind. Informat., vol.8, no.4, pp.889-899, Nov. 2012. 
9. Peerapat Vithayasrichareon, Graham Mills, Iain F. MacGill, "Impact of Electric Vehicles and Solar PV on Future Generation Portfolio Investment," IEEE Trans. Sustain. Energy, vol.6, no.3, pp.899-908, July. 2015.

10. João C. Ferreira, A. Silva, Vítor Monteiro, João L. Afonso. "Collaborative Broker for Distributed Energy Resources," in Computational Intelligence and Decision Making, 1st ed., A.Madureira, C.Reis, V.Marques, Ed. Springer, 2013, pp.367-378

11. Juan Van Roy, Niels Leemput, Frederik Geth, Jeroen Büscher, Robbe Salenbien, Johan Driesen, "Electric Vehicle Charging in an Office Building Microgrid With Distributed Energy Resources,” IEEE Trans. Sustain. Energy, vol.5, no.4, pp.1389-1396, Oct. 2014.

12. C. Gouveia, D. Rua, F. Ribeiro, L. Miranda, J. M. Rodrigues, C. L. Moreira, J. A. Peças Lopes, "Experimental Validation of Smart Distribution Grids: Development of a Microgrid and Electric Mobility Laboratory," ELSEVIER Electrical Power and Energy Systems, vol.78, pp.765-775, June 2016.

13. Mingrui Zhang, Jie Chen, "The Energy Management and Optimized Operation of Electric Vehicles Based on Microgrid," IEEE Trans. Power Del., vol.29, no.3, pp.1427-1435, June 2014.

14. C. Jin, J. Tang, and P. Ghosh, “Optimizing Electric Vehicle Charging: A Customer's Perspective," IEEE Transactions on Vehicular Technology, vol. 62, no. 7. pp. 2919-2927, Sep-2013.

15. Mithat C. Kisacikoglu, Burak Ozpineci, LeonM. Tolbert, "EV/PHEV Bidirectional Charger Assessment for V2G Reactive Power Operation," IEEE Trans. Power Electron., vol.28, no.12, pp.5717-5727, Dec. 2013.

16. Matthias D. Galus, Marina Gonzalez Vaya, Thilo Krause, Goran Andersson, "The Role of Electric Vehicles in Smart Grids," John Wiley and Sons, WIREs Energy Environ, vol.2, pp.384-400, Aug. 2013.

17. Vehbi C. Gungor, Dilan Sahin, Taskin Kocak, Salih Ergut, Concettina Buccella, Carlo Cecati, Gerhard P. Hancke, "Smart Grid and Smart Homes - Key Players and Pilot Projects," IEEE Ind. Electron. Mag., vol.6, pp.18-34, Dec. 2012.

18. Vítor Monteiro, J. G. Pinto, João L. Afonso, "Operation Modes for the Electric Vehicle in Smart Grids and Smart Homes: Present and Proposed Modes", IEEE Transactions on Vehicular Technology, vol.65, no.3, pp.1007-1020, Mar. 2016.

19. A. R. Boynuegri, M. Uzunoglu, O. Erdinc, E. Gokalp, "A new perspective in grid connection of electric vehicles: Different operating modes for elimination of energy quality problems," ELSEVIER Applied Energy, vol.132, pp.435-451, Nov. 2014.

20. Mosaddek Hossain Kamal Tushar, Chadi Assi, Martin Maier, Mohammad Faisal Uddin, "Smart Microgrids: Optimal Joint Scheduling for Electric Vehicles and Home Appliances," IEEE Trans. Smart Grid, vol.5, no.1, pp.239-250, Jan. 2014.

21. Vítor Monteiro, João Paulo Carmo, J. G. Pinto, João L. Afonso, “A Flexible Infrastructure for Dynamic Power Control of Electric Vehicle Battery Chargers," IEEE Trans. Veh. Technol., vol.65, no.6, pp.4535-4547, June 2016.

22. J. G. Pinto, Vítor Monteiro, Henrique Gonçalves, Bruno Exposto, Delfim Pedrosa, Carlos Couto, João L. Afonso, "Bidirectional Battery Charger with Grid to Vehicle, Vehicle to Grid and Vehicle to Home Technologies," IEEE IECON Industrial Electronics Conference, pp.5934-5939, Vienna Austria, Nov. 2013.

23. Vítor Monteiro, Bruno Exposto, João C. Ferreira, João L. Afonso, "Improved Vehicle-toHome (iV2H) Operation Mode: Experimental Analysis of the Electric Vehicle as Off-Line UPS,” IEEE Transactions on Smart Grid, vol.8, no.6, pp.2702-2711, Nov. 2017. 
24. Vítor Monteiro, João C. Ferreira, Andrés A. Nogueiras Meléndez, João L. Afonso, "Model Predictive Control Applied to an Improved Five-Level Bidirectional Converter," IEEE Trans. Ind. Electron., vol.63, no.9, pp.5879-5890, Sept. 2016.

25. Vitor Monteiro, João C. Ferreira, Andres A. Nogueiras Melendez, Carlos Couto, João L. Afonso, "Experimental Validation of a Novel Architecture Based on a Dual-Stage Converter for Off-Board Fast Battery Chargers of Electric Vehicles," IEEE Trans. Veh. Tech., vol.67, no.2, pp.1000-1011, Feb. 2018.

26. Vítor Monteiro, Andrés A. Nogueiras Meléndez, Carlos Couto, João L. Afonso, "Model Predictive Current Control of a Proposed Single-Switch Three-Level Active Rectifier Applied to EV Battery Chargers," IEEE IECON Industrial Electronics Conference, Florence Italy, pp.1365-1370, Oct. 2016.

27. Vítor Monteiro, João C. Ferreira, Delfim Pedrosa, João L. Afonso, "Comprehensive Analysis and Comparison of Digital Current Control Techniques for Active Rectifiers," CONTROLO Portuguese Conference on Automatic Control, Guimarães - Portugal, pp.655-666, Sept. 2016. 